\section{Dr. Cohen replies}

\section{To the Editor:}

We thank Dr. Koumakis and colleagues for their interest in our report ${ }^{1}$.

A few cases of spondyloarthritis ( $\mathrm{SpA}$ ) treated by tocilizumab have been published. The report of Koumakis and colleagues is interesting for many reasons: (1) they described the case of a woman with a severe radiographic ankylosing spondylitis (AS) on spine and sacroiliac joints; (2) for the first time, tocilizumab was administered because of recurrent infections [under 2 anti-tumor necrosis factor (TNF)] and not inefficacy; (3) the clinical response was rapid; and (4) the spinal inflammation studied by magnetic resonance images decreased, in contrast to other cases ${ }^{2,3}$.

This new successful case of tocilizumab in SpA provided the opportunity to address the following issues: (1) the difference in the efficacy of tocilizumab between patients refractory or intolerant to anti-TNF; (2) the efficacy of tocilizumab as first-line biologic, as reported ${ }^{3,4}$; and (3) the necessity to adapt the frequency of infusions as in juvenile idiopathic arthritis for the systemic form compared to the polyarticular form.

Unfortunately, in addition to recent and disappointing case series reports with (at least) axial $\mathrm{SpA}^{5,6}$, the development of tocilizumab in AS has been interrupted by Roche because the NCT01209702 study, a randomized, double-blind, placebo-controlled study including patients refractory to nonsteroidal antiinflammatory drugs, failed to show the efficacy of tocilizumab.

Actually, the role of interleukin 6 (IL-6) in SpA does not seem unequiv$\mathrm{ocal}^{7,8,9}$. Finally, the absence of efficacy of tocilizumab demonstrated in a placebo-controlled study suggests that there is not a pathogenic role of IL-6 in $\mathrm{SpA}$ as in rheumatoid arthritis. Recent reports on inadequate response in peripheral $\mathrm{SpA}^{10}$ and psoriatic arthritis ${ }^{11}$ follow this hypothesis.

JEAN-DAVID COHEN, MD, Hopital Lapeyronie - Unité

d'Immuno-Rhumatologie, 191 Avenue du Doyen Gaston Giraud, Montpellier 34295, France. E-mail: jd-cohen@chu-montpellier.fr

\section{REFERENCES}

1. Koumakis E, Feydy A, Kahan A, Allanore Y. Interleukin 6 blockade in spondyloarthritis. J Rheumatol 2012;39:xxxxx.

2. Henes JC, Horger M, Guenaydin I, Kanz L, Koetter I. Mixed response to tocilizumab for ankylosing spondylitis. Ann Rheum Dis 2010;69:2217-8.
3. Shima Y, Tomita T, Ishii T, Morishima A, Maeda Y, Ogata A, et al Tocilizumab, a humanized anti-interleukin-6 receptor antibody, ameliorated clinical symptoms and MRI findings of a patient with ankylosing spondylitis. Mod Rheumatol 2011;21:436-9.

4. Tanaka T, Kuwahara Y, Shima Y, Hirano T, Kawai M, Ogawa M, et al. Successful treatment of reactive arthritis with a humanized anti-interleukin-6 receptor antibody, tocilizumab. Arthritis Rheum 2009;61:1762-4.

5. Del Castillo Piñol N, Gossec L, Sparsa L, Roux C, Dougados M. Tocilizumab for treatment of refractory spondylarthritis: report of 5 patients. Ann Rheum Dis 2011;70:343.

6. Dudler J, Aubry-Rozier B. Tocilizumab in axial spondylarthropathies: about 18 cases. Ann Rheum Dis 2011;70:128.

7. Hayer S, Niederreiter B, Nagelreiter I, Smolen J, Redlich K. Interleukin 6 is not a crucial regulator in an animal model of tumour necrosis factor-mediated bilateral sacroiliitis. Ann Rheum Dis 2010;69:1403-6.

8. Falkenbach A, Herold M, Wigand R. Interleukin-6 serum concentration in ankylosing spondylitis: a reliable predictor of disease progression in the subsequent year? Rheumatol Int 2000;19:149-51.

9. Collado-Escobar MD, Nieto A, Mataran L, Raya E, Martin J. Interleukin 6 gene promoter polymorphism is not associated with ankylosing spondylitis. J Rheumatol 2000;27:1461-3.

10. Malochet-Guinamand S, Soubrier M. Mixed effect of tocilizumab in spondylarthritis. Comments about the article by Wendling, et al, entitled "Short-term effect of IL-6 inhibition in spondylarthritis". Joint Bone Spine 2010;77:624-5. Joint Bone Spine 2011 Oct 29 [E-pub ahead of print].

11. Ogata A, Umegaki N, Katayama I, Kumanogoh A, Tanaka T. Psoriatic arthritis in two patients with an inadequate response to treatment with tocilizumab. Joint Bone Spine 2012;79:85-7.

J Rheumatol 2012;39:5; doi:10.3899/jrheum.111603 